\title{
A CONSTITUIÇÃO DOCENTE NA FORMAÇÃO INICIAL E A ESCUTA SUPERVISIVA COM BASE NA TEORIA HOLÍSTICA DA ATIVIDADE
}

\author{
Leila Bom Camilo
}

\begin{abstract}
Resumo: Este texto propõe uma reflexão teórica, no contexto de estágio supervisionado do Curso de Licenciatura em Letras da UFSM, referente à escuta supervisiva no processo de constituição docente. Com base na Teoria Holística da Atividade, a escuta supervisiva busca acompanhar o estagiário, pautada na empatia, na congruência e na aceitação incondicional. A supervisão passa a ser uma base segura que acolhe, orienta e encoraja o acadêmico na inserção da nova profissão. Essa escuta se dá na dimensão afetivo-identificatória, em que ocorre a relação entre a nucleação nomotética com a objetivação idiográfica. Nesse processo, o estagiário passa por uma crescente diferenciação do saber, conscientizando-se dele. $\mathrm{Na}$ formação do sujeito do pensar-sentir-agir, a Teoria Holística da Atividade (THA) contempla não só os processos sociocognitivos, mas também os processos semióticos afetivo-identificatórios, em que numa aliança didática entre Universidade, acadêmico e escola, se estabelece o Desenvolvimento Profissionalizante Corresponsável (DPC). Dessa forma, a THA mostra-se melhor equipada para atender as demandas do mercado e reduzir os conflitos do entorno do sistema.
\end{abstract}

Palavras-chave: Teoria Holística da Atividade, escuta supervisiva, constituição docente em Letras.

Resumen: Este artículo propone una reflexión teórica, en la etapa de contexto supervisado Licenciatura en Letras, UFSM, refiriéndose a la escucha supervisiva de la enseñanza en el proceso de la constitución profesional. Sobre la base de la Teoria Holística da Atividade, la escucha supervisiva busca monitorear el alumno, basado en la empatía, la congruencia y la aceptación incondicional. La supervisión se convierte en una base segura que acoge, orienta y anima a la inclusión de la nueva profesión académica. Esta escucha se produce en la dimensión afectivo-identificatorio, en que ocurre la relación entre la nucleación nomotética con la objetivación idiográfica. En este proceso, el alumno se somete a una diferenciación cada vez mayor de conocimientos, tomando conciencia de ellos. En la formación del sujeto del pensar-sentir-actuar, el THA abarca no sólo los procesos cognitivos sociales, sino también los procesos semióticos-afectivos identificatorio, en el que una alianza didáctica entre la Universidad, académico y escolar, asienta un Desarrollo Profesional Corresponsable (DPC ). De este modo, el THA se muestra estar mejor equipada para satisfacer las demandas del mercado y reducir los conflictos que rodean el sistema.

Palabras clave: Teoría Holística de la actividad; escucha supervisiva, constitución del maestro en Letras.

\footnotetext{
${ }_{1}$ Professora na Universidade Federal de Santa Maria/ Centro de Educação - Departamento de Metodologia do Ensino de Língua Portuguesa. Mestre em Letras - Lingüística Aplicada pela Universidade Católica de Pelotas (2005). Doutoranda em Letras na Universidade Federal de Santa Maria. Pesquisa na área de ensino-aprendizagem da língua portuguesa na Educação Básica. Email: leilabomcamillo@hotmail.com
} 


\section{Introdução}

O contexto de supervisão de estágio do Curso de Licenciatura em Letras/Português é um espaço privilegiado em que se acompanha uma transição do acadêmico, que sai da condição de aluno para professor atuante em sala de aula. A inserção nessa nova realidade, nesse novo papel social, não se dá de um momento para outro. Sentir-se professor, atuar e pensar como um educador linguístico requer uma nova percepção simbólica, uma ocupação num novo lugar.

A Teoria Holística da Atividade (THA) afirma que é a partir do atolinguodidático que uma classe profissional se constitui e se fortalece sistemicamente. Nos discursos, mais especificamente nos fluxos discursivos, realizase outra transição: a de uma representação simbólica fragmentada do professor de Letras para uma representação simbólica integrada, que possa lidar com os conflitos externos.

Em razão disso, este texto busca refletir teoricamente sobre a constituição docente na formação inicial do educador linguístico. Tal discussão traz em pauta a escuta supervisiva com os novos avanços da THA, na versão 4.3.

A THA apresenta três metafatores imbricados no paradigma holístico: os fatores de atribuição, os fatores de mediação e os fatores de controle. Este estudo traz um recorte do enquadramento, enfatizando as práticas constitutivas dos fatores de atribuição. Uma das contribuições da supervisão de estágio para a formação inicial é orientar o acadêmico na apropriação do papel docente. Nesse sentido, é nas práticas constitutivas que encontramos sustentação teórica para tal prática. Vejamos seus principais conceitos.

\section{As práticas constitutivas}

Segundo Richter (2008), as práticas constitutivas cumprem função caracterizadora, iconizante dos diversos aspectos do exercício profissional. Dizem respeito a cognições profissionais e à apropriação em si do papel, são elas responsáveis pela construção da identidade e dos imaginários que a alimentam.

Tais práticas presidem à organização do trabalho e têm como modalidade geradora o nível alético-epistêmico. Esse nível responde pelo exercício funcional subdividido em contextos institucionais, pela diferenciação/especialização e pelos paradigmas de trabalho.

Esse metafator refere-se à modelagem do papel social, ou seja, a identificação, a introjeção e o acoplamento ${ }^{2}$, bem como responde às questões relativas à estabilização e à preservação do papel no ecossistema social, compondo

\footnotetext{
${ }^{2}$ Luhmann (2009, p.128) conceitua acoplamento estrutural como sendo a interrelação entre diferentes sistemas autopoiéticos, consequentemente, autônomos. Richter afirma que a THA parte da ideia de que a sociedade e o ser humano constituem tipos diferentes de sistemas, disjuntos e acoplados, exercendo influência mútua incessante e considera central o papel social para a caracterização dessa interface.
} 
dessa forma o fundo sociointerativo dos eventos de intervenção especializada. Nesse caso denomina ao supervisor de estágio a ação linguodidática na medida em que cria/constitui fenômenos sistêmicos.

Tais práticas manifestam-se discursivamente com mecanismos que a reconstituem e a reconstroem. Dessa forma, postulam a autopoiese ${ }^{3}$ discursiva, com formações discursivo-ideológicas autodelimitantes e autoperpetuantes.

Segundo Richter (2008, p. 59-61), as práticas constitutivas respondem ao problema da elaboração discursiva do papel profissional delimitando os seguintes aspectos:

I. Bens sociais a produzir, os valores a estes conferidos e, por metonímia, os valores atribuídos aos próprios profissionais.

II. Os relacionamentos profissionais, que se estabelecem no interior do sistema de atividade, entre pares, e na relação sistemo-entorno, entre profissionais e não-profissionais.

III. A organização do trabalho, a qual, se exercida endogenamente ${ }^{4}$, é indissociável de sua função autopoiética, ao pautar-se basicamente pelo cuidado de associar o empenho pela qualidade do bem social produzido à preservação dos fatos e instrumentos vinculados a essa produção.

No âmbito dos fatores de atribuição do enquadramento da THA, as práticas constitutivas contemplam no nível alético-epistêmico a construção identitária a partir de duas operações fundamentais: a de experienciação e a de dupla contingência.

A THA considera central o conceito de papel social para a caracterização da interface sociedade e ser humano. Para Richter, o papel é um parâmetro duplamente perspectivado para 0 profissional, assim possibilita 0 seguinte desdobramento:

a) Papel concebido como manifestação particular de um coletivo. Em última análise, o sujeito fica reabsorvido no fator comunidade (profissional), realizando na prática o que, em termos de grupo, está pré-estipulado abstrata e potencialmente. É também o correlato semiótico intrasubjetivo (transcendental) de uma relação.

b) Papel concebido como conjunto de atitudes-condutas frente ao cliente (que é, por sua vez, também interpelado no seu papel correlativo), equacionadas singular e precisamente na interface profissional-leigo. É também o correlato semiótico inter-subjetivo (físico-objetivo) de uma relação. (RICHTER, 2008, p. 53)

\footnotetext{
${ }^{3}$ Segundo Luhmann (2009, p.120) entende-se por autopoiesis, que o sistema se produz a si mesmo, além de suas estruturas. Os sistemas são autônomos a nível das operações. Ou seja, a categorização da autopoiesis assume a autonomia, a qual significa que somente a partir da operação do sistema é possível determinar o que lhe é relevante e o que lhe é indiferente.

${ }^{4}$ A endogenia engloba, segundo Richter (2008, p.14), três efeitos discursivos: efeito de prestígio (valores), efeito de legitimidade (conduta, atitude) e efeito de verdade (respaldo declarativoconceitual).
} 
A construção identitária na perspectiva sistêmica contempla então duas operações: as operações $\psi$ e as operações $\sum$. As operações $\psi$, ou sistemas $\psi$, referem-se à experienciação, mais especificamente aos sistemas impulsivos somados aos sistemas reflexivos; e as Operações $\Sigma$, ou sistemas $\sum$, referem-se aos sistemas sociais e sua relação com a comunicação explicada pela dupla contingência.

Ao referirmo-nos aos sistemas sociais, estamos tratando de sistemas sociais luhmannianos definidos com base em processos comunicativos. Nesse sentido, a THA $(2008,2011)$ admite para os sistemas sociais um tipo de atividade, a comunicação; e sustenta que essa comunicação se dá como conjunto e sucessão temporal de operações de redução de complexidade do entorno na condição de dupla contingência.

A THA sustenta que a interface subjetividade-experienciação considera os processos discursivos exógenos (referem-se à falsidade constitutiva) e os processos discursivos endógenos (referem-se à autenticidade constitutiva). Assim a exogenia reafirma um papel não integrado da profissão, com a ausência de paradigma e enquadramento; enquanto a endogenia constitui um papel integrado, com a presença de um paradigma e um enquadramento. Nessa perspectiva, a intersubjetividade individual é indissociável à subjetividade social.

A construção identitária corresponde no enquadramento da THA, aos seguintes conceitos: a apropriação do papel docente e o exercício profissional.

- A formação do papel está associada a dois processos que ocorrem no grupo profissional: a dimensão afetivo-identificatória e 0 Desenvolvimento Profissional Corresponsável (DPC).

- O exercício profissional: que representa os contextos institucionais, a diferenciação/especialização e os paradigmas do enquadramento.

Vejamos cada um desses conceitos.

\section{A apropriação do papel}

A THA indaga a respeito de como transformar o conjunto de pessoas formadas em Letras em uma classe profissional com noções éticas, procedimentais, com exercício responsável e legal da profissão.

Para a formação do papel profissional, um postulado importante da THA é de que nós temos que produzir nossos desejos e seguranças com base em lugares sociais que tenham práticas e condições seguras. Nesse sentido, serão desenvolvidos a seguir dois conceitos: a dimensão afetivo-identificatória e 0 desenvolvimento profissional corresponsável no contexto de estágio.

A dimensão afetivo-identificatória refere-se à relação entre a supervisora e o estagiário, em que se estabelece uma relação do vínculo social para que o processo 
constitutivo seja significativo. A supervisão de estágio passa a ser uma base segura para a inserção profissional do acadêmico no campo de trabalho.

Estudos psicanalíticos, que influenciaram o conceito de base segura, sugerem fortemente o nascimento dos processos semióticos ainda por volta dos oito meses de idade do bebê. Mahler (1993) e Winnicott (1975, 1983), estudando o desenvolvimento emocional da criança de zero até cerca de seis anos, destacam a primeira relação afetiva desde a mais tenra idade, a relação entre mãe e bebê.

Tais estudos consideram que os signos afetivos que mãe e bebê trocam são os primeiros sinais de comunicação. O desenvolvimento da percepção e das trocas afetivas precede todas as outras funções psíquicas que se desenvolverão a partir dos fundamentos fornecidos pelas trocas afetivas. Os afetos parecem manter esse desenvolvimento até o final do primeiro ano de vida.

Segundo Mahler (1993), o nascimento psicológico do sujeito se dá com o processo de separação-individuação, o qual consiste em separar-se ontologicamente da mãe e tornar-se progressivamente um ser humano autônomo, sem abdicar do senso de segurança proporcionado pelo outro. Isso, particularmente, no que diz respeito às experiências do próprio corpo do sujeito e ao principal representante do mundo como a criança o experimenta, o objeto primário de amor.

A separação e a individuação são concebidas como desenvolvimentos complementares: a separação consiste na saída da criança da fusão simbiótica com a mãe, "corre ao longo da diferenciação, distanciamento, formação de fronteiras e desligamento da mãe" (MAHLER, 1993, p.71). E a individuação consiste nas aquisições que marcam o momento em que a criança assume suas próprias características individuais, "a evolução da autonomia intrapsíquica, percepção, memória, cognição, teste de realidade" (MAHLER, 1993, p.71). É nesta fase que o sujeito conquista sua identidade.

Para Winnicott (1975), é nos primeiros estágios do desenvolvimento afetivo que se encontra o nascimento dos processos semióticos representados pelo objeto transicional: "O objeto transicional representa a transição da criança pequena que passa do estado de união com a mãe ao estado de relação com ela, enquanto algo externo e separado. (WINNICOTT, 1975, p.14)

O objeto transicional significa uma fase intermediária na qual os objetos em que $\mathrm{o}$ bebê se relaciona são ao mesmo tempo, paradoxalmente, criados e encontrados. No conceito de objeto transicional, não é o 'objeto' que conta, mas o qualificativo 'transicional', é a utilização que se faz dele. É o espaço potencial, uma localização da experiência cultural.

O objeto transicional é símbolo de um objeto caso esse objeto esteja presente, conferindo-lhe valor. Assim, o objeto transicional será um apoio representativo da mãe se ela estiver presente. Caso a mãe desapareça, o objeto transicional tende a morrer enquanto tal. 
A criança não tem uma clara distinção entre o que é externo e o que é interno, o que é criado e o que é encontrado, entre as suas fantasias e os fatos eles mesmos. Quando o simbolismo é empregado, em que o bebê conquista essas diferenciações, ele estará claramente distinguindo entre fantasia e fato, entre objetos internos e objetos externos.

Todo esse processo ontogenético postulado por Winnicott, é aqui descrito para destacar que o mesmo será reproduzido metaforicamente ao longo da vida em qualquer circunstância. Na vida adulta, encontramos metáforas sociais desta relação objetal. No caso presente, o outro profissional mais experiente representa o objeto de valor transicional na apropriação do papel docente.

A THA busca responder a essa questão trazendo o conceito de base segura de Bowlby para a dimensão afetivo-identificatória na formação inicial. A base segura baseia-se na teoria do apego de Bowlby $(1989,2002)$.

Para Bowlby (1989), o vínculo social se dá em toda e qualquer relação social em que ocorre o comportamento de apego e o comportamento de cuidado. Ele define um comportamento de cuidado, para lidar com o comportamento de apego, como sendo a provisão de uma base segura a partir da qual se pode explorar o mundo exterior e a ele retornar certos de que serão bem-vindos, confortados se houver um sofrimento e encorajados se estiverem inseguros ou com medo.

$O$ autor ainda enfatiza que essencialmente o comportamento de cuidado refere-se a estar disponível, "pronto para responder quando solicitado, para encorajar e, talvez, dar assistência, porém só intervindo ativamente quando for claramente necessário" (BOWLBY, 1989, p.25).

A teoria se desenvolveu a partir das relações objetais, da perda temporária ou permanente da figura materna. Segundo Bowlby

\begin{abstract}
Como o desenvolvimento do comportamento de apego é um sistema organizado, que tem como objetivo a manutenção da proximidade ou do acesso a uma figura materna discriminada, requer da criança 0 desenvolvimento de sua capacidade cognitiva para que mantenha sua mãe na memória quando esta não está presente; essa capacidade se desenvolve durante a segunda metade do primeiro ano de vida. Dessa forma, dos nove meses em diante, a grande maioria das crianças respondem com protesto e choro ao fato de serem deixadas com uma pessoa estranha e, também, ficando de mau-humor e rejeitando o estranho por tempo mais ou menos prolongado. Essas observações demonstraram que, durante esses meses, a criança está se tornando capaz de representações e que o modelo funcional, que ela tem de sua mãe, está se tornando disponível com o propósito de comparação durante sua ausência e reconhecimento depois de seu retorno (BOWLBY, 1989, p.120).
\end{abstract}

Um traço importante do comportamento de apego é a intensidade da emoção que o acompanha, o tipo de emoção que surge de acordo com a qualidade da relação entre a pessoa apegada e a figura de apego. Em contrapartida 0 comportamento de cuidado responde com acolhimento incondicional. 
A provisão de uma base segura para a construção do papel profissional permite que sejam reelaboradas as percepções profissionais. Assim, uma comunidade de prática segura passa a ser uma metáfora de base segura, o que no simbólico equivale a um lugar solidamente constituído. A supervisão de estágio como uma base segura exerce as funções de acolher, orientar e encorajar o estagiário na tomada de decisões a partir de uma escuta sensível.

\section{A escuta supervisiva}

A escuta é uma ação linguística que requer uma troca simbólica entre os interlocutores. Numa abordagem interacionista, Bakhtin define a escuta como uma compreensão ativamente responsiva com 'tonalidades e ressonâncias' 'dialógicas' e 'polifônicas'.

O autor diz que

todo o falante é por si mesmo um respondente em maior ou menor grau: porque ele não é o primeiro falante, o primeiro a ter violado o eterno silêncio do universo, e pressupõe não só a existência do sistema da língua que usa mas também de alguns enunciados antecedentes -dos seus e alheios com os quais o seu enunciado entra nessas ou naquelas relações. Cada enunciado é um elo na corrente complexamente organizada de outros enunciados. Desse modo, o ouvinte com sua compreensão passiva, que é representado como parceiro do falante nos desenhos esquemáticos das lingüísticas gerais, não corresponde ao participante real da comunicação discursiva (BAKHTIN, 2003, p.272).

Para Bakhtin o ouvinte concorda, discorda e completa as significações do discurso, ou seja, ele compreende a palavra do locutor opondo-a a uma contrapalavra.

Toda compreensão da fala viva, do enunciado vivo é de natureza ativamente responsiva (embora o grau desse ativismo seja bastante diverso); toda compreensão é prenhe de resposta, e nessa ou naquela forma a gera obrigatoriamente: o ouvinte se torna falante. A compreensão passiva do significado do discurso ouvido é apenas um momento abstrato da compreensão ativamente responsiva real e plena, que se atualiza na subseqüente resposta em voz alta (BAKHTIN, 2003, p.271).

Bakhtin (2003) ainda afirma que o que determina a escuta de um enunciado é o quanto é levado em conta a percepção do próprio enunciado pelo destinatário, até que ponto que o ouvinte está a par da situação, dispõe de conhecimentos especiais de um dado campo cultural da comunicação; que considera as concepções e conviç̧ões, os preconceitos (próprio ponto de vista) as simpatias e antipatias. Essa percepção irá determinar também as escolhas discursivas, o estilo dos enunciados.

Vygotsky (1998), ao estudar a relação entre a linguagem verbal e o pensamento, apresenta sociocognitivamente 0 nascimento dos processos semióticos pela palavra, ou seja, nossas primeiras escutas. Assim o autor 
desenvolve o conceito de internalização ao referir-se ao elo entre a consciência e o meio social.

Para ele, internalização é "a reconstrução interna de uma operação externa" (1998, p. 74). E isso se dá tendo como signo mediador a linguagem verbal.

$\mathrm{Na}$ dimensão afetivo-identificatória, a escuta contempla os conceitos rogerianos de empatia, congruência e aceitação incondicional. Segundo Rogers (2009), à medida que compreendo os sentimentos e pensamentos, que os vejo como o outro vê, e os aceito como ao outro, é que a pessoa se sente realmente livre para explorar todos os cantos de sua experiência interior e frequentemente enterrada. Ele denomina esse aspecto como sendo uma compreensão empática profunda, que possibilita ver seu mundo particular através de seus olhos. Quando isso acontece, quem auxilia torna-se uma companhia para quem está sendo auxiliado, acompanhando-o na busca de si mesmo, onde ele se sente livre para ingressar.

O autor afirma que o terapeuta experimenta uma compreensão aguda e empática do mundo do cliente, como se fosse visto do interior. Para Rogers empatia é "captar o mundo particular do cliente como se fosse o seu próprio mundo, mas sem nunca esquecer esse caráter de 'como se' - é isso a empatia, que surge como essencial no processo" (ROGERS, 2009, p.327).

Rogers (2009, p.59) define congruência da seguinte forma: "Com este termo pretendo dizer que qualquer atitude ou sentimento que estivesse vivenciando viria acompanhado da consciência dessa atitude". Ainda esclarece que "quando isso é verdade, sou, naquele momento, uma pessoa unificada e inteirada e é então que posso ser o que sou no mais íntimo de mim mesmo. Esta é uma realidade que, por experiência, proporciona aos outros confiança". (ROGERS, 2009, p.59)

Para abordar a aceitação incondicional, Rogers (2009) diz que no processo de tornar-se pessoa, de mudança da personalidade, o indivíduo passa por sete estágios de desenvolvimento progressivo. Ele afirma que a uma condição básica para acompanhar esse processo é a aceitação incondicional.

Ao tentar conceituar o processo de mudança, Rogers afirma que mudança é um 'contínuo' e não uma entidade com atributos específicos. Assim os indivíduos não se movem de um ponto fixo para um novo ponto fixo, mas, em suas palavras "o contínuo mais significativo é o que vai da fixidez para a mobilidade, da estrutura rígida para o fluxo, da estase para o processo" (ROGERS, 2009, p.148).

Para a THA, a escuta em formação inicial e continuada não é necessariamente uma escuta binária de gabinete. Ela está presente também na relação triádica do Desenvolvimento Profissional Corresponsável, e é nesta que se podem estabelecer traços diferenciais entre o nomotético e o ideográfico, na medida em que os três lugares da relação assumem se pronunciar no jargão conceitual de sua prática profissional (por exemplo, em vez de julgar uma tarefa pelo "gostaram, 
sorriram", julga-se por: "os alunos tiveram de chegar às ideias-suporte da ideia principal do parágrafo recuperando a relação de meio-fim por implicitação").

Esse procedimento leva às assimetrias discursivas necessárias para constituir e expandir operações sistêmicas cada vez mais diferenciadas do seu entorno, cada vez mais normativas e mais próximas do desejado limiar da autopoiese.

$\mathrm{Na}$ relação triádica do discurso formativo, a aliança e a confiança mútuas entre os lugares vão então favorecer a diferenciação entre, de um lado, as operações capazes de serem extrapoladas para dois ou três lugares no tempo e no espaço (o nomotético) e, de outro, as operações de personalização, de "estilo" ao lidar com as categorias teórico-metodológicas de consenso (o idiográfico).

Isso tem a ver também com a diferenciação de Leontiev entre ações (que correspondem na THA ao nomotético) e operações (que correspondem na THA ao idiográfico). Portanto, a rotação produtiva entre os quatro fluxos discursivos vai ter como pré-requisito a relação de aliança e confiança a três lugares do DPC.

Os discursos mobilizados na dimensão afetiva-identificatória estão tanto nos saberes gnoseológicos, quanto praxeológicos. Ou seja, no âmbito do saber-sobre e do saber-como. Um espírito corporativo dá sustentação para questões voltadas para os diversos aspectos da profissão.

A construção identitária num senso de parceria favorece a integralidade do sistema. Nesse ponto, a THA propõe um desenvolvimento profissional corresponsável (DPC) e estabelece uma metodologia de ação para a efetivação da aliança didática.

\section{Desenvolvimento Profissional Corresponsável (DPC)}

O Desenvolvimento Profissional Corresponsável (DPC) consiste numa triangulação-horizontalizaçao profissional com o objetivo de proceder à capacitação integrada inicial e em-serviço e o concomitante fortalecimento da classe.

A THA estabelece a condição de uma aliança profissional (no caso aliança linguodidática): a) para atividades-fim (centralizadas em objeto ou motivo): profissional da academia, profissional do mercado e clientela. b) para atividadesmeio (centralizadas em recursos humanos): profissional da academia, profissional do mercado e graduando, que podem ser também denominados supervisor, cosupervisor e supervisionando.

Para a THA, essa aliança pode se alimentar de interações presenciais e/ou a distância, síncronas e assíncronas. Além disso, está pressuposto o conhecimento, pelos profissionais e profissionalizandos, do princípio central do enquadramento, seus fatores e níveis.

No Desenvolvimento Profissionalizante Corresponsável, a aliança didática centra-se em discussões a partir das demandas do mercado, destacando questões 
no jargão enquadrativo, que, ao equacioná-las, volta-se discursivamente para o enquadramento relacionando-as.

A aliança didática promove uma relação identitária por meio de dois processos constitutivos, um referente à subjetividade individual e outro à subjetividade social, denominados respectivamente de nucleação nomotética e objetivação idiográfica.

A nucleação nomotética refere-se aos saberes que são frutos de uma sedimentação mediada - a ideia de integrar conhecimentos específicos da atividade social regrada. Representa uma integração entre prática e reflexão consistente do papel.

A objetivação idiográfica representa o estilo ou as características que têm a ver com a solução e as iniciativas próprias do acadêmico. Que ele saiba reparar-se como indivíduo - é a própria maneira de conduzir, tem o controle dos conceitos vinculados e conhecidos.

Há no nomotético a ocupação do lugar de professor, nele se busca a contratualidade, com papéis, funções. O papel a ser exercido não é aquele que o estagiário está sendo no idiográfico, então ele busca uma referência no nomotético para seguir adiante e volta-se para o idiográfico, para ir constituindo-se.

\section{0 exercício funcional}

O exercício funcional está atrelado aos contextos institucionais. No próprio exercício, a diferenciação/especialização vai se constituindo a partir dos paradigmas de enquadramento.

$O$ acadêmico enfrenta processos subjetivos e intersubjetivos. Os processos subjetivos guardam uma interface social via linguagem, e os processos intersubjetivos são influenciados pelo entorno, pelo contexto intersubjetivo. $O$ sujeito se projeta na linguagem permeabilizando o que entra e o que sai.

Perls (1997) chama o entorno de campo interacional, em que fatos históricos e culturais estão intrínsecos à maneira pela qual todo problema é apresentado. $O$ autor aborda o campo e o contato como inseparáveis, uma vez que não se separa a experiência do lugar em que ela acontece.

Assim, duas proposições são tratadas em conjunto: a de que a experiência é essencialmente contato, o funcionar da fronteira entre o organismo e seu ambiente; e que toda função humana é um interagir num campo organismo/ambiente sociocultural, animal e físico.

Num espaço de supervisão de estágio, estagiário e supervisora fazem parte do mesmo campo de experiência, e a atitude de cada um interfere com a do outro, assim é na aliança didática, no encontro dos três sujeitos envolvidos. O campo é percebido aqui como o contexto funcional e operacional da profissão. 
O enquadramento ou paradigmação do exercício profissional é um conceito complexo, envolvendo a apropriação de um papel, a constituição de um senso de aliança e respeito com os pares, ética com os pares e clientes, adoção de abordagem laboral compartilhada (fundamentação teórica e prática), senso de finalidade e critérios de controle, tudo isso interconectado.

A institucionalização implica trabalhar com sistemas abertos, pois estamos aí na esfera administrativa (o que será melhor tratado na TA de Engeström) e, além disso, em cada área institucional como saúde, educação, mídia, direito etc. Há múltiplas profissões que entram com diferentes interações batesonianas (simétricas, complementares e recíprocas) e, portanto, múltiplas relações de cooperação, antagonismo ou subserviência.

Para a THA, basta pensarmos nas práticas exercitivas da atribuição, com seus discursos do déficit e da demanda, que precisam ser respectivamente combatidos e cultivados - e isso vai depender do fortalecimento da relação entre academia, mercado e sociedade [por exemplo, criação de entidades que representem uma abordagem de trabalho (um paradigma) ou uma esfera de atribuições, e não apenas grupos de pesquisa da academia, pois esta restrição contribui para o abismo existente entre academia e mercado, perpetuando a relação de subalternidade entre atividades-meio (Universidade) e atividades-fim (escolas, no caso de Licenciatura] e a alopoiese que assola nossa profissão.

\section{Conclusão}

A constituição docente na formação inicial a partir da escuta baseada nos pressupostos da THA se dá a partir da relação nomotética e idiográfica, em que o estagiário, ao mesmo tempo que conserva sua singularidade, conscientiza-se de um saber laboral constituído no grupo ao qual pertence.

A escuta supervisiva volta-se para a diferenciação desse saber em que observa, ao longo do processo de apropriação do papel, uma assimetria crescente. A partir da escuta empática, congruente e de aceitação, a supervisão, como uma base segura, encontra-se melhor equipada para lidar com os conflitos do entorno.

Ao resgatar o nascimento dos processos semióticos afetivos, além dos já contemplados processos semióticos sociocognitivos (internalização), a THA consegue aproximar-se significativamente na natureza do processo didático que envolve o sujeito do pensar-agir-sentir. Nesse sentido, avança na qualificação da formação inicial em que discursivamente sai de um lugar mais fragmentado de papel docente para um lugar mais integrado.

\section{Referências}

BAKHTIN, Mikhail. Estética da criação verbal. 4. ed. São Paulo: Martins Fontes, 2003.

BENJAMIN, Alfred. A entrevista de ajuda. São Paulo: Martins Fontes, 1978. 
BOWLBY, John. Uma base segura: aplicações clínicas da teoria do apego. Porto Alegre: Artes Médicas, 1989.

Apego: a natureza do vínculo. São Paulo: Martins Fontes, 2002.

LUHMANN, Niklas. Introdução à Teoria dos Sistemas. Petrópolis: Vozes, 2009.

MAHLER, Margaret S. O nascimento psicológico da criança: simbiose e individuação. Porto Alegre: Artes Médicas, 1993.

RICHTER, Marcos Gustavo. Rumo a uma concepção holística de formação docente. Expressão, Santa Maria, v. 1, p. 120-124, 2004.

Formação de professores, emancipação, profissionalização. Expressão, Santa Maria, v. 1, p. 112-118, 2005.

Série Cogitare.

Aquisição, representação e atividade. Santa Maria: PPGL UFSM, 2008.

Profissionalização docente segundo a teoria holística da atividade: estudo empregando software de mapeamento semântico. In: LEÃO, Rosaura A.; MOTTA, Vaima A. (Org.) Linguagem e Interação: o ensino em pauta. São Carlos: Pedro \& João Editores, 2011.

PERLS, Frederick Salomon. Gestalt-terapia. São Paulo: Summus, 1997.

ROGERS, Carl. Tornar-se pessoa. 6. ed. São Paulo: Martins Fontes, 2009.

VIGOTSKI, Lev. S. A construção do pensamento e da linguagem. 2. ed. São Paulo: Martins Fontes, 2009.

A formação social da mente: o desenvolvimento dos processos psicológicos superiores. 6. ed. São Paulo: Martins Fontes, 1998.

WINNICOTT, D. W. O ambiente e os processos de maturação: estudos sobre a teoria do desenvolvimento emocional. Porto Alegre: Artmed, 1983.

. O brincar e a realidade. Rio de Janeiro: Imago, 1975. 